\title{
Multivariate analysis of the copepod community of near-shore waters in the western Gulf of Maine
}

\author{
C. A. Manning*, A. Bucklin \\ Ocean Process Analysis Laboratory and Department of Zoology, University of New Hampshire, 142 Morse Hall, Durham, \\ New Hampshire 03824, USA
}

\begin{abstract}
Abundance patterns were described for 15 species of planktonic copepods in coastal waters of the western Gulf of Maine, NW Atlantic, between April 2002 and March 2003. Vertically stratified sampling was carried out at 4 stations along a $12 \mathrm{~km}$ cross-shelf transect ranging from $60 \mathrm{~m}$ to $105 \mathrm{~m}$ depth offshore of Portsmouth, NH, USA. Temporal and spatial patterns of distribution and abundance were described for adult copepods, and multivariate analyses were used to assess trends in community composition. Three species, Oithona similis, Temora longicornis, and Centropages typicus, dominated the community numerically, comprising $72.1 \%$ of all copepods identified. The abundances of 7 species exhibited strong seasonal variation, in contrast to 5 species which were abundant throughout the year. As shown by non-metric multi-dimensional scaling (MDS), the composition of the community changed in a cyclical pattern over the 1 yr period, suggesting a clear seasonal cycle. There was significant vertical partitioning of the copepod community, with significant differences among depth strata at all but the shallowest station. In contrast, significant horizontal spatial variation was evident only in the deepest stratum; surface and mid-depth samples did not differ among the 4 stations. Although many of the same species found in this study are also known from Georges Bank and Massachusetts Bay, their seasonal patterns of abundance differed notably among the regions. Such dissimilarities emphasize the importance of sampling at appropriate time and space scales in order to accurately assess population and community dynamics of coastal zooplankton assemblages.
\end{abstract}

KEY WORDS: Zooplankton · Copepods · Coastal processes · Multi-dimensional scaling $\cdot$ Gulf of Maine

Resale or republication not permitted without written consent of the publisher

\section{INTRODUCTION}

Planktonic copepods in the Gulf of Maine have been extensively sampled (Bigelow 1924, Davis 1987, Kane 1993, Licandro et al. 2001), yet patterns of distribution and abundance in the coastal waters of Maine and New Hampshire are not completely known. Copepods consistently dominate the zooplankton assemblages of this region both in numbers and biomass (Bigelow 1924, Kane 1993). As phytoplankton grazers and active predators, copepods play an important role in the transition of energy from primary producers to higher consumers. Larval stages of many commercially important fish species prey primarily on copepods (Sherman et al.
1998), and copepod abundance directly affects recruitment success of these fish. Quantifying the temporal and spatial abundance patterns of copepods in coastal areas of the Gulf of Maine is thus essential to understanding the regional ecosystem.

The Gulf of Maine is enclosed by shallow coastal waters of the United States and Canada to the north and west. The Western Maine Coastal Current tends to flow south along the coasts of Maine and New Hampshire, herein termed the Western Maine Coastal Region (WMCR). This region is stratified in summer months and mixed to a depth of approximately $100 \mathrm{~m}$ in winter (Bisagni et al. 1996). It is a nutrient rich zone with high phytoplankton productivity (Durbin 1997) 
that in turn supports an abundant copepod community (Bigelow 1924, Turner 1994). Water from the WMCR may feed Massachusetts Bay and Georges Bank, acting as a supply for copepod species to these areas (Durbin 1997), although the degree to which this occurs is still debated (McGillicuddy et al. 1998). To date, the WMCR has not been as comprehensively sampled as Georges Bank or Massachusetts Bay. As a result, it is unclear how similar the patterns of variation in the WMCR copepod community will be to patterns described for these other shallow, productive areas in the Gulf of Maine.

The behavior of planktonic copepods can significantly influence how they are transported by local water currents. Copepods can swim strongly enough to overcome diffusive processes and potentially even turbulent mixing (Wiafe \& Frid 1996, Lagadeuc et al. 1997), enabling them to control their vertical location in the water column to some extent (Ambler \& Miller 1987, Incze et al. 2001). This is significant because water currents often vary in both speed and direction across vertical gradients in the water column. Two copepods at the same location, vertically separated by only $50 \mathrm{~m}$, may be transported kilometers apart within $24 \mathrm{~h}$. The vertical distribution of individual species is thus critical to understanding and predicting copepod population dynamics.

For 2 cryptic species in the WMCR, Pseudocalanus moultoni and $P$. newmani, very little knowledge of seasonal and spatial patterns exists. The species have not been differentiated in most zooplankton studies due to their morphological similarity. They can now be readily identified using a species-specific polymerase chain reaction (SS-PCR) that has been used to discriminate these species in studies on Georges Bank (Bucklin et al. 1998, Bucklin et al. 2001). The objectives of this study are to describe individual species' patterns of distribution and abundance in the WMCR and to determine the degree of change in the composition of the copepod community over monthly time scales and small (1 to $10 \mathrm{~m})$ to coarse (10 to $100 \mathrm{~m}$ ) space scales. We report here the results of analysis of monthly zooplankton collections at appropriate horizontal and vertical resolution, characterization of hydrographic structure of the water column, and molecular discrimination of cryptic species, in order to provide a detailed picture of the dynamics of the copepod community of the WMCR.

\section{MATERIALS AND METHODS}

Samples were collected at approximately monthly intervals from 4 stations along a cross-shelf transect in the coastal waters offshore of Portsmouth, NH, USA from April 2002 to March 2003 (Fig. 1). The length and position of the transect was chosen to minimize sampling of estuarine output; stations were located at 60 , 80, 90, and $105 \mathrm{~m}$ depth. Zooplankton samples were collected using a $1 / 4 \mathrm{~m}^{2}$ Multiple Opening Closing Net and Environmental Sensing System (MOCNESS, Wiebe et al. 1985), with $150 \mu \mathrm{m}$ mesh nets and inte-

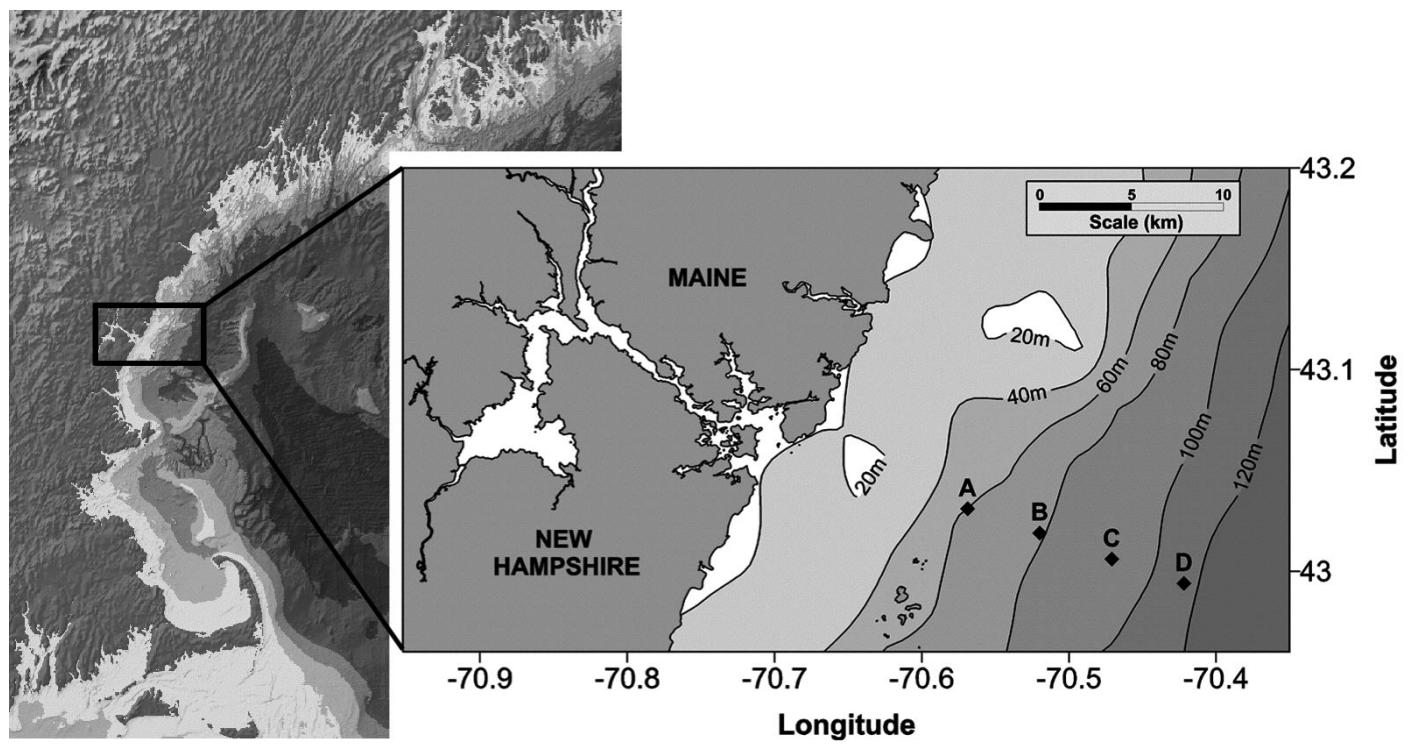

Fig. 1. Location of sampling stations, indicated by A, B, C, and D. Station coordinates are as follows: Stn A: $43.031^{\circ} \mathrm{N}, 70.569^{\circ} \mathrm{W}$; Stn B: $43.019^{\circ} \mathrm{N}, 70.519^{\circ} \mathrm{W}$; Stn C: $43.011^{\circ} \mathrm{N}, 70.472^{\circ} \mathrm{W}$; Stn D: $42.994^{\circ} \mathrm{N}, 70.422^{\circ} \mathrm{W}$. (Gulf of Maine image by E. Roworth and R. P. Signell) 
grated CTD. The volume of water sampled by each net was determined using a flow meter mounted on the net frame and an on-board inclinometer to record the area of the net opening. Real-time CTD data relayed to the ship as the MOCNESS was lowered were used to locate the pycnocline (defined as a sharp gradient in temperature and/or salinity separating 2 depths of different densities) and thus to select the depths of 3 discrete samples taken during the uphaul. Samples were taken within $5 \mathrm{~m}$ of the bottom to $5 \mathrm{~m}$ below the pycnocline (the 'deep' sample), through the pycnocline ('midwater'), and from $5 \mathrm{~m}$ above the pycnocline to the surface ('surface'). If no pycnocline existed, the water column was equally divided between the 3 samples. On average, the surface net sampled down to $19 \mathrm{~m}$, the midwater net sampled between 19 and $42 \mathrm{~m}$, and the deep sample was from 42 to within $5 \mathrm{~m}$ of the bottom. Zooplankton samples were preserved in $95 \%$ ethanol immediately after retrieval and the ethanol was changed after $24 \mathrm{~h}$.

A Folsom plankton splitter was used to divide an aliquot of approximately 200 adult copepods from the original sample (mean aliquot size $=212$ copepods, $\mathrm{SD}=97.0$ ), requiring splits of $1 / 8$ to $1 / 1024$. All adult copepods in this aliquot were identified to species and counted. Species count data were transformed into densities (number per $\mathrm{m}^{3}$ ) using the dilution factor of the subsample and the volume of water sampled by that net. Copepod biomass was estimated using the formula determined by Davis \& Wiebe (1985):

$$
\text { Wet weight }(\mathrm{mg})=0.086\left(\text { Length }^{2.809}\right)
$$

Lengths used in the formula were average prosome lengths (mm) taken from previously published work (Wilson 1932, Johnson 1934, Lawson \& Grice 1970, Murphy \& Cohen 1978, Frost 1989, Gerber 1999).

Pseudocalanus spp. were identified to species utilizing a multiplexed, competitive species-specific polymerase chain reaction (SS-PCR, Bucklin et al. 2001). Female Pseudocalanus spp. were sorted from the subsample and 24 individuals were randomly chosen for identification by SS-PCR. At least 20 successful PCR identifications were done for samples in which Pseudocalanus spp. comprised at least $5 \%$ of adult copepods. Densities for each species were determined by the proportion of SS-PCR identified P. moultoni and P. newmani in each aliquot multiplied by the total number of Pseudocalanus spp. counted in the original subsample. Differences in vertical distribution between the 2 species of Pseudocalanus were tested using split-plot analysis of variance (ANOVA). The response variable used in the ANOVA was the abundance of a species in the deep strata subtracted from the abundance of that species in the surface strata, calculated for each individual MOCNESS tow. Two ANOVA were performed: one for periods of water column stratification (April 2002-October 2002), and one for periods of mixing (November 2002-March 2003).

Patterns of species diversity were assessed by evaluating 2 characteristics of each sample: species richness (i.e. number of species found in a sample) and evenness (see Pielou 1975). Pielou's evenness index $\left(J^{\prime}\right)$ ranges from near 0 (indicating the community is heavily dominated by 1 species) to 1 (indicating that all species have identical abundances).

Copepod densities for the 15 most numerous species were visualized in section plots generated using Surfer version 7 (Golden Software), with interpolation by linear kriging. An anisotropy ratio of 0.16 , which compensates for the discrepancy in the scales of the axes, was selected after analyzing copepod densities to determine correlation length scales in both the horizontal (i.e. station to station) and vertical (i.e. average depth sampled by each net) dimensions. On average, a horizontal change of $8 \mathrm{~km}$ was equivalent to a vertical change of $50 \mathrm{~m}$. Multivariate data analysis and diversity analysis was done using PRIMER (Plymouth Routines In Multivariate Ecological Research) version 5.2.9 (PRIMER-E). For multivariate analyses, the absolute densities of each species were natural $\log [\ln (x+1)]$ transformed, to reduce the potential effect of sampling error. Bray-Curtis similarities were used to generate a similarity matrix of all pair wise comparisons of samples, based on the transformed densities.

Non-metric multi-dimensional scaling (MDS) was used to analyze temporal and spatial changes in the copepod community. MDS plots are generated from a ranked similarity matrix, such that the distance from one point to another is representative of the similarity between those points (Clarke 1993). The closer 2 points are in the resulting plot, the more similar the copepod assemblages between those samples. The degree to which the distances between all points in the plot accurately represent the similarity between them is measured by the stress value. A stress value of less than 0.1 indicates the plot accurately represents similarities, while a stress value of greater than 0.3 indicates the points are close to being randomly placed (Clarke 1993).

The significance of both temporal and spatial variation in community composition was tested using a 2way crossed Analysis of Similarities for unreplicated data (ANOSIM2) routine in PRIMER (Clarke \& Warwick 1994). This analysis generates an average Spearman correlation coefficient, $\rho$, for all pairwise comparisons between ranked similarity matrices of among-treatment groups in each block. For example, when testing the significance of depth and sample date at $\mathrm{Stn} A$, ranked similarity matrices of all depths at each sample date are compared (using only samples 
taken at $\mathrm{Stn} A)$. The resulting $\rho$ value is close to zero when there is no correlation in the order of ranked similarities; a value of 1 indicates perfect correlation of the ranked similarities in all matrices. Significance levels are determined by comparison with values produced by random permutations of the data.

a
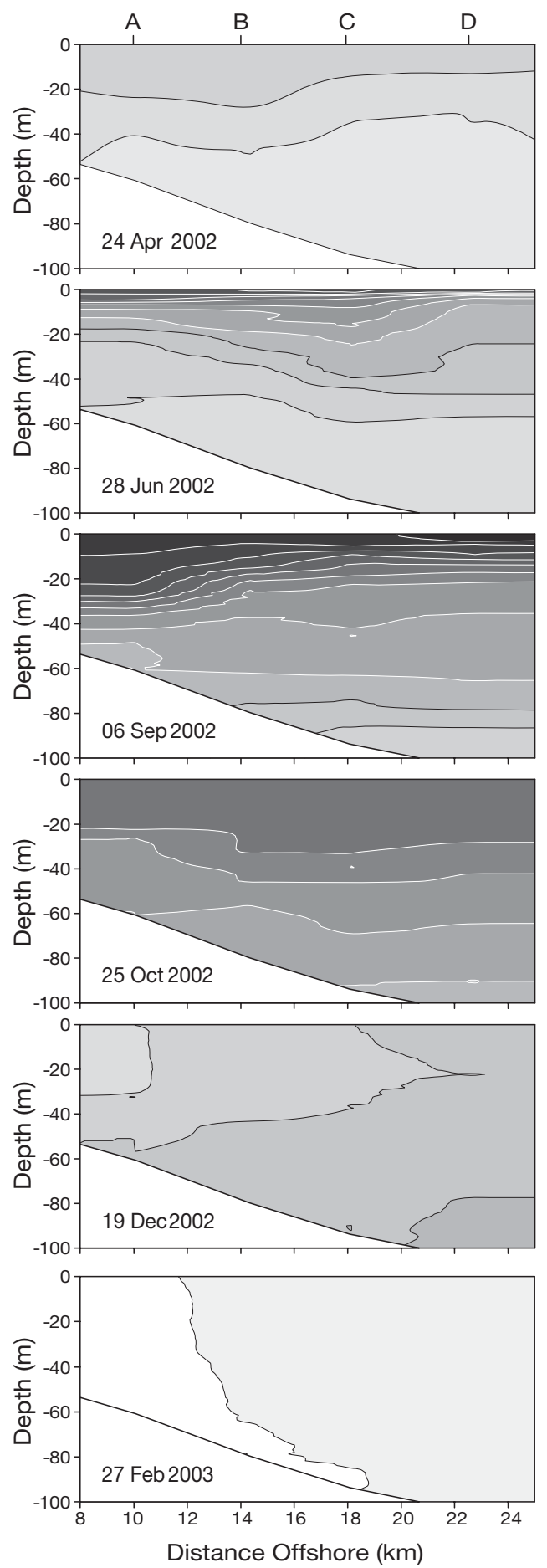

\section{RESULTS}

The water column was stratified from April to October 2002 and was completely mixed from November 2002 to March 2003. Temperature ranged from a minimum of $2.5^{\circ} \mathrm{C}$ on 27 February 2003 to a surface
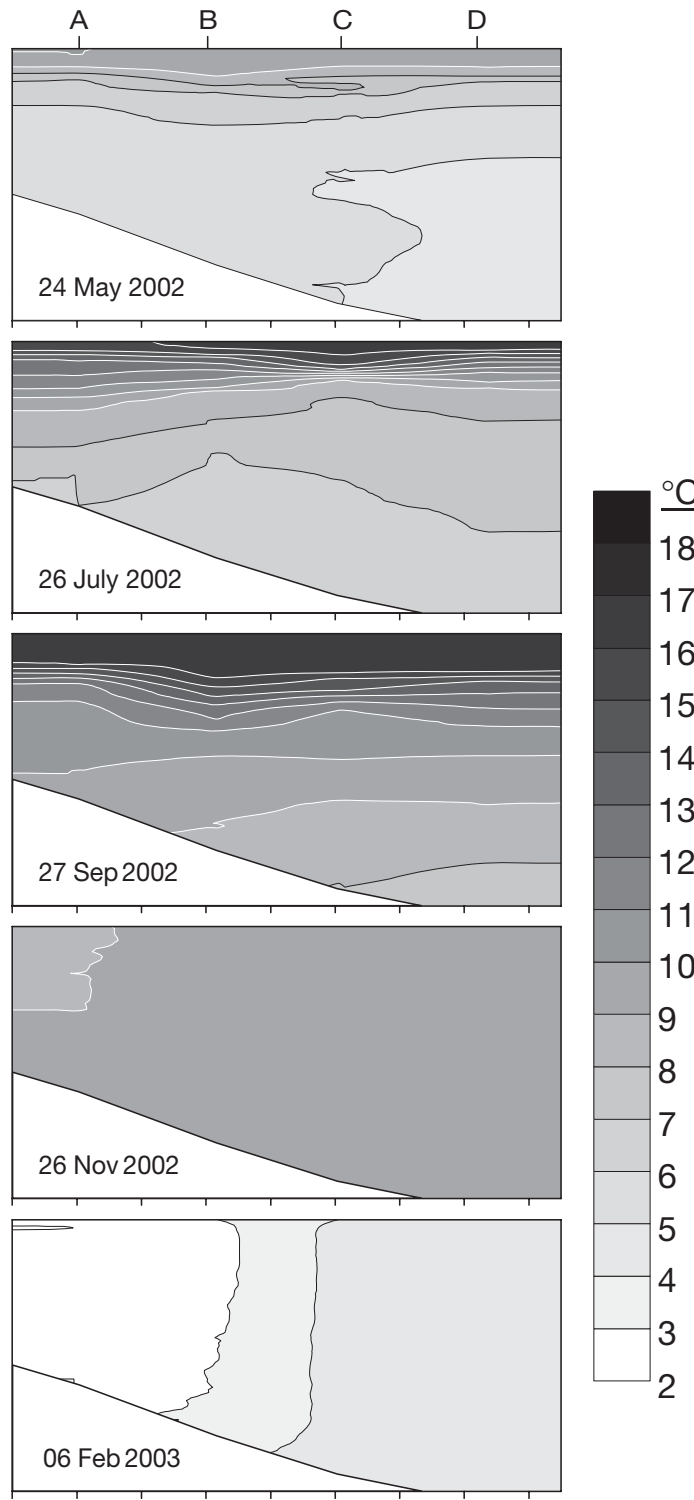

16

15

14

13

12

11

10

9

8

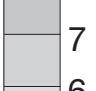

6
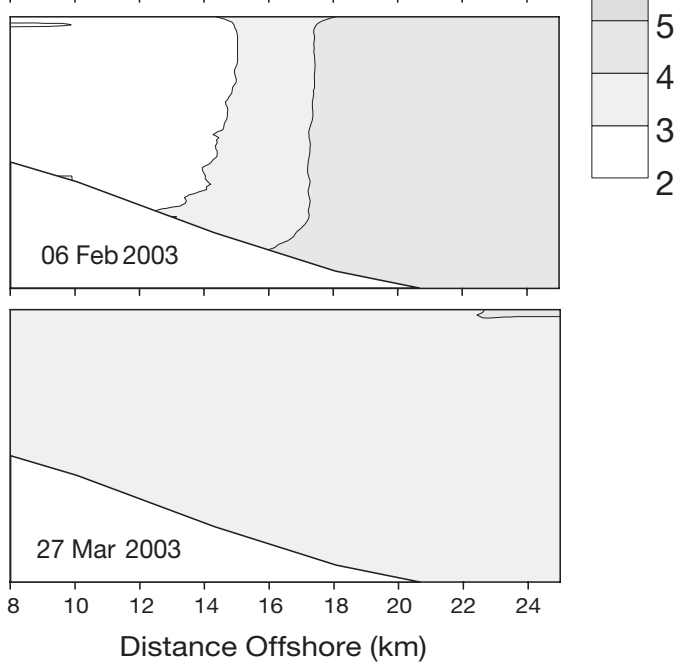

Fig. 2. Above and facing page. Section plots of (a) temperature, and (b) salinity, as sampled by MOCNESS tows at each station 
maximum of $18^{\circ} \mathrm{C}$ on 6 September 2002 (Fig. 2a). Salinity ranged from a surface low of $30.4 \mathrm{ppt}$ on 24 May 2002 to a maximum of 33.2 ppt on 6 February 2003 (Fig. 2b). Data for water currents at 6 different depths were obtained from the Gulf of Maine Ocean Observing System (GOMOOS; www.gomoos.org)
Buoy B, located approximately $16 \mathrm{~km} \mathrm{NNE}$ of the transect. Over the period of this study flow was generally SSE, paralleling the coastline (Fig. 3). Surface ( $2 \mathrm{~m}$ ) currents had velocities up to 5 times greater than deep (54 m) currents; the direction of flow was similar at all depths.

b
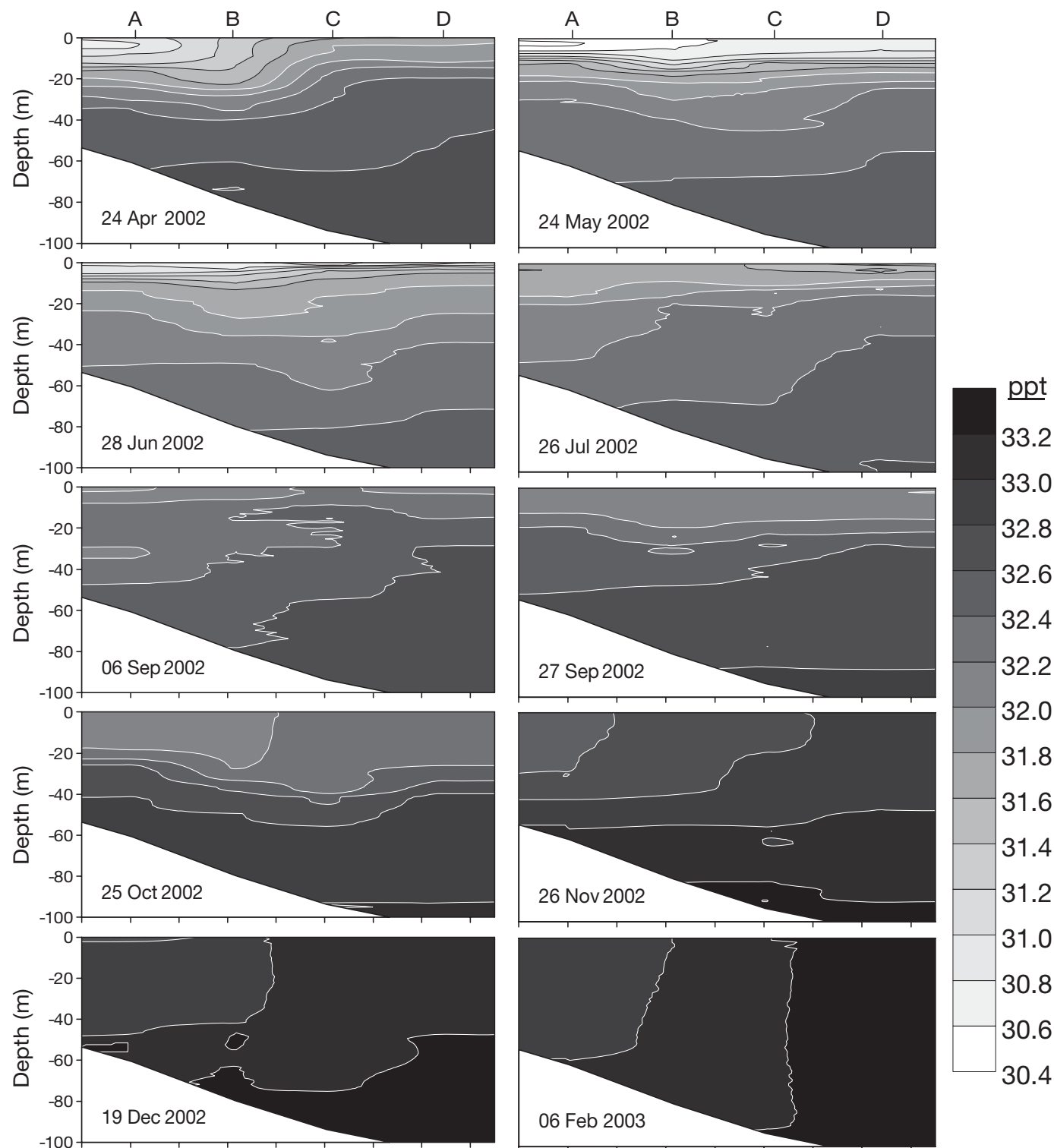

33.2

33.0

32.8

32.6

32.4

32.2

32.0

31.8

31.6

31.4

31.2

31.0
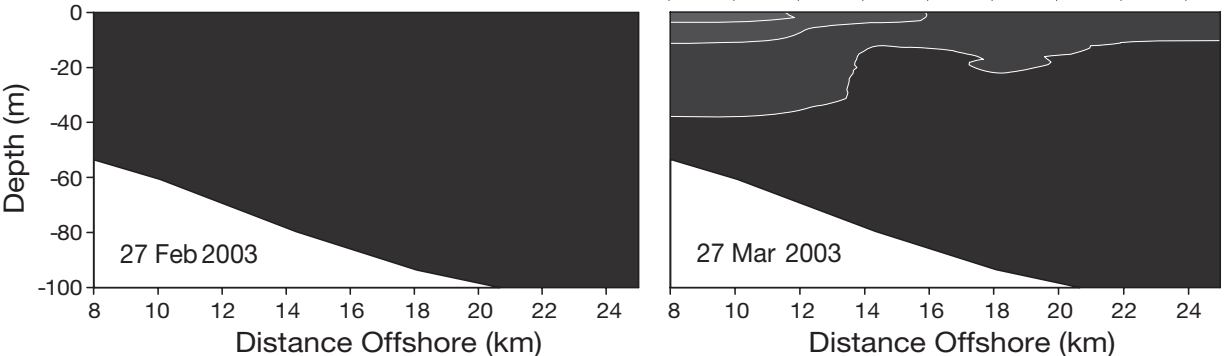

30.8

30.6

30.4

Fig. 2. (continued) 

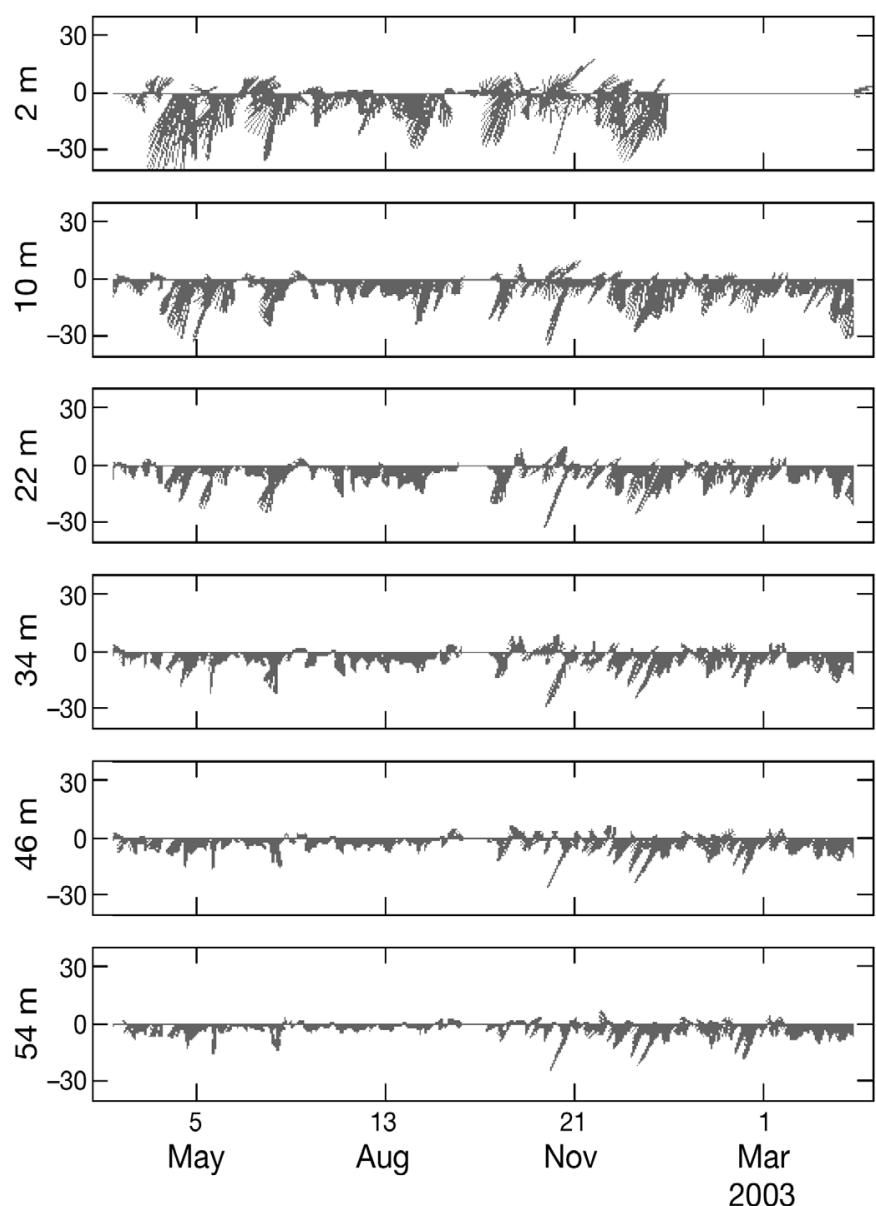

Fig. 3. Residual ocean currents for 6 depths as recorded by GOMOOS Buoy B, located roughly $16 \mathrm{~km}$ NNE of transect $\left(43.181^{\circ} \mathrm{N}, 70.428^{\circ} \mathrm{W}\right)$. Data for this plot were filtered by GOMOOS to remove tidal currents. Direction of line indicates compass direction of current; for example, a line pointing straight up indicates a flow due north, while a line pointing to the right would indicate a flow to the east. $y$-axis scale is in $\mathrm{cm} \mathrm{s}^{-1}$. (Courtesy of www.gomoos.org.)

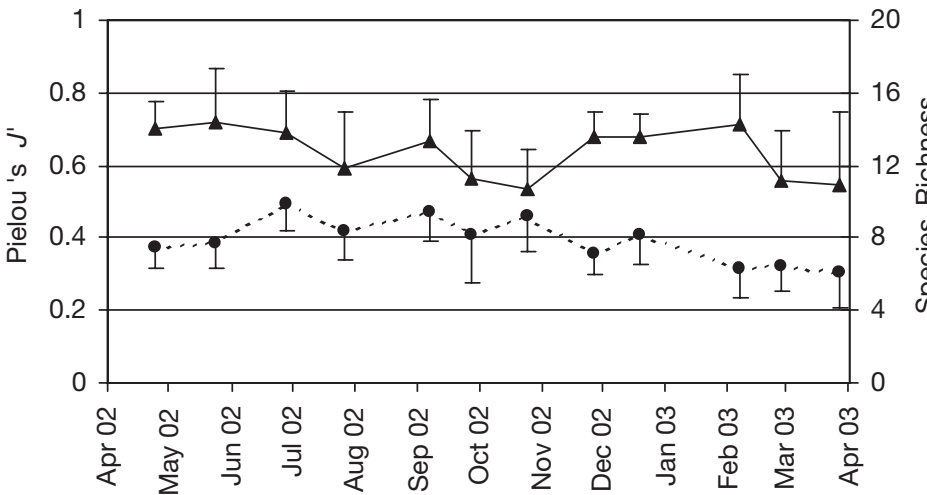

Fig. 4. Pielou's $J^{\prime}$ (evenness, indicated by solid line) and species richness (number of species, indicated by dashed line) averaged for each sample date. Error bars are 1 standard deviation; they are shown only above or below the line for clarity
Adults of 21 copepod species were recorded in the plankton samples taken from the WMCR. The average species richness found in an aliquot was 7.87 ( $\mathrm{SD}=2.00$ ), and the average evenness (Pielou's $J^{\prime}$ ) was 0.637 ( $\mathrm{SD}=0.142$ ). Species richness was highest in summer and fall samples; evenness did not fluctuate significantly by season (Fig. 4). Oithona similis, Temora longicornis, and Centropages typicus comprised $72 \%$ of all copepods identified; T. longicornis, Calanus finmarchicus, and C. typicus made up $78 \%$ of total biomass, considering adults only (Table 1). Total

Table 1. Contribution of each species to overall density and biomass

\begin{tabular}{|c|c|}
\hline$\%$ total & Species \\
\hline \multicolumn{2}{|l|}{ Density } \\
\hline 30.47 & Oithona similis \\
\hline 26.06 & Temora longicornis \\
\hline 15.57 & Centropages typicus \\
\hline 5.97 & Acartia longiremis \\
\hline 5.93 & Pseudocalanus newmani \\
\hline 3.81 & Pseudocalanus moultoni \\
\hline 3.52 & Calanus finmarchicus \\
\hline 2.16 & Acartia hudsonica \\
\hline 1.85 & Paracalanus parvus \\
\hline 1.29 & Microcalanus pusillus \\
\hline 1.21 & Centropages hamatus \\
\hline 0.74 & Oithona atlantica \\
\hline 0.64 & Eurytemora herdmani \\
\hline 0.57 & Metridia lucens \\
\hline 0.53 & Clausocalanus pergens \\
\hline 0.13 & Microsetella norvegica \\
\hline 0.04 & Tortanus discaudatus \\
\hline 0.02 & Parvocalanus crassirostris \\
\hline 0.02 & Acartia tonsa \\
\hline 0.002 & Paraeuchaeta norvegica \\
\hline 0.001 & Euchaeta marina \\
\hline \multicolumn{2}{|l|}{ Biomass } \\
\hline 31.85 & Temora longicornis \\
\hline 24.91 & Calanus finmarchicus \\
\hline 21.45 & Centropages typicus \\
\hline 4.34 & Acartia longiremis \\
\hline 3.90 & Oithona similis \\
\hline 3.79 & Pseudocalanus moultoni \\
\hline 2.97 & Pseudocalanus newmani \\
\hline 1.93 & Metridia lucens \\
\hline 1.52 & Acartia hudsonica \\
\hline 1.37 & Centropages hamatus \\
\hline 0.56 & Paracalanus parvus \\
\hline 0.43 & Eurytemora herdmani \\
\hline 0.42 & Oithona atlantica \\
\hline 0.19 & Tortanus discaudatus \\
\hline 0.18 & Clausocalanus pergens \\
\hline 0.17 & Microcalanus pusillus \\
\hline 0.15 & Paraeuchaeta norvegica \\
\hline 0.02 & Microsetella norvegica \\
\hline 0.02 & Acartia tonsa \\
\hline 0.006 & Euchaeta marina \\
\hline 0.004 & Parvocalanus crassirostris \\
\hline
\end{tabular}




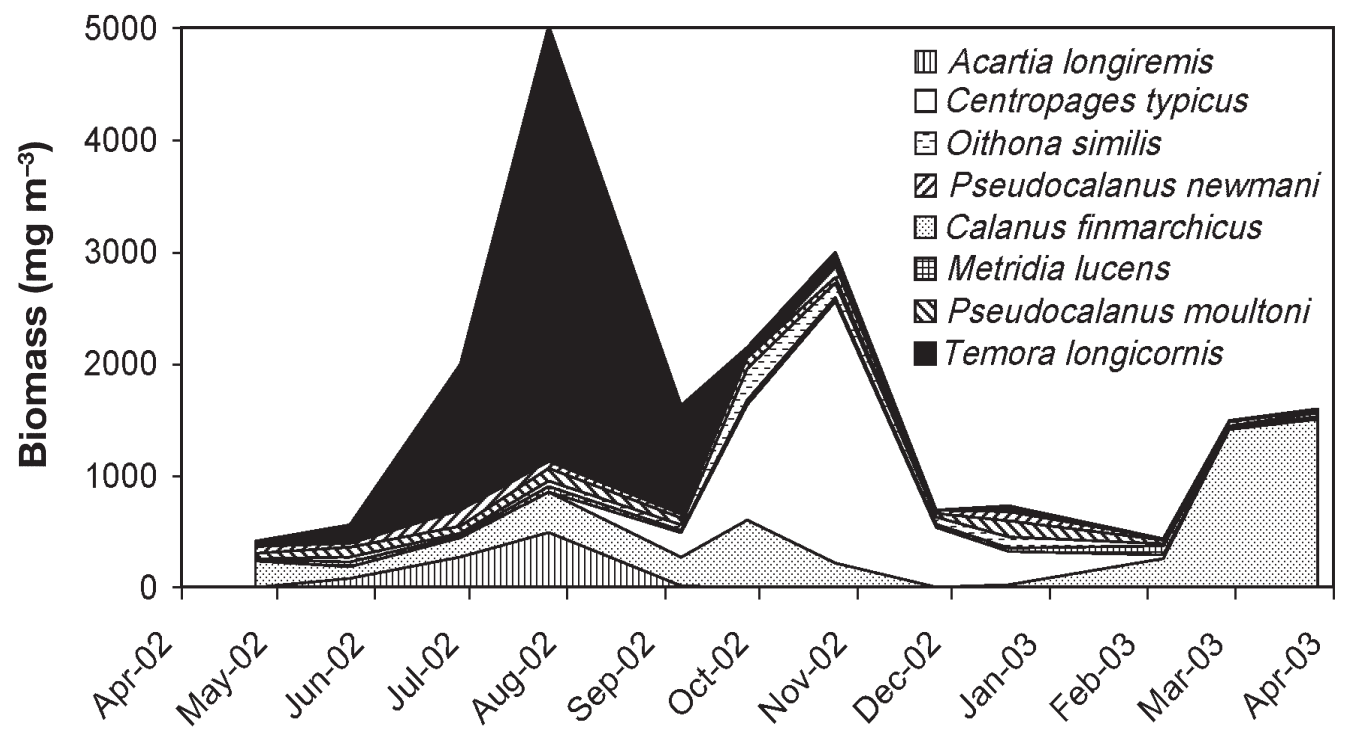

Fig. 5. Total biomass of the 8 most abundant species of planktonic copepods, averaged across station and depth

adult copepod biomass in this study peaked in July (Fig. 5). This sample date also had the highest total density, largely due to the abundance of Temora longicornis.

Copepod species in the study were categorized based on their temporal and spatial abundance patterns: adult Oithona similis, Metridia lucens, and Microcalanus pusillus were recorded year-round and showed significant vertical abundance gradients. $O$. similis was generally found in higher numbers in the surface net (Fig. 6a), while M. lucens and M. pusillus were relatively more abundant in deep samples and almost absent from surface samples (Fig. 6b and c, respectively). Calanus finmarchicus, Oithona atlantica, Pseudocalanus moultoni, and $P$. newmani were present throughout the year but showed no consistent pattern of vertical distribution. C. finmarchicus was more prevalent in deep samples from late spring through fall, but was much more abundant in early spring in surface water (Fig. 7a). O. atlantica was sporadically present throughout much of the sampling period and showed no clear pattern of vertical distribution (Fig. 7b). The 2 species of Pseudocalanus showed different vertical distributions during periods of stratification (ANOVA, $\mathrm{p}<0.05$ ), but were not significantly different after the water column was mixed. P. moultoni was more abundant in deep samples when the water column was stratified and $P$. newmani more abundant in surface samples throughout the year (Fig. 7c and $d$, respectively).

The remaining species exhibited strong seasonal changes in abundance: Acartia hudsonica, A. longiremis, Centropages hamatus, Eurytemora herdmani, and Temora longicornis were most abundant in June and July, and formed a distinct summer community. A. hudsonica and $A$. longiremis had similar seasonal patterns of vertical distribution: both were most abundant in surface samples in spring and were present throughout the water column at their summer peak (Fig. 8a and b). When present, C. hamatus and E. herdmani were more abundant in surface samples (Fig. 8c and d). T. longicornis reached greater density in July than any other species over the course of the study, with highest densities closer to shore (Fig. 9a). Centropages typicus, Clausocalanus pergens, and Paracalanus parvus had highest abundances in October and November and differentiated the fall community (Fig. 9b-d). C. typicus and P. parvus were more abundant in surface samples, while $C$. pergens was uniformly vertically distributed.

The multi-dimensional scaling plot of all samples described a cyclical seasonal pattern of community composition; with few exceptions, there was a clockwise progression from one month to the next (Fig. 10a,b). Individual MDS plots for each month showed that samples generally clustered by depth, indicating the community had less variability among stations than among depth strata (Fig. 11).

The patterns visible in the MDS plots were statistically supported by the ANOSIM2 test (Table 2). Sample date had a significant effect on copepod composition at each individual station and depth (i.e. the ranked similarities of samples from all collection dates tended to follow the same month-to-month pattern at each station, and at each depth). The effect of depth was significant at Stns B, C, and D, which indicated the 

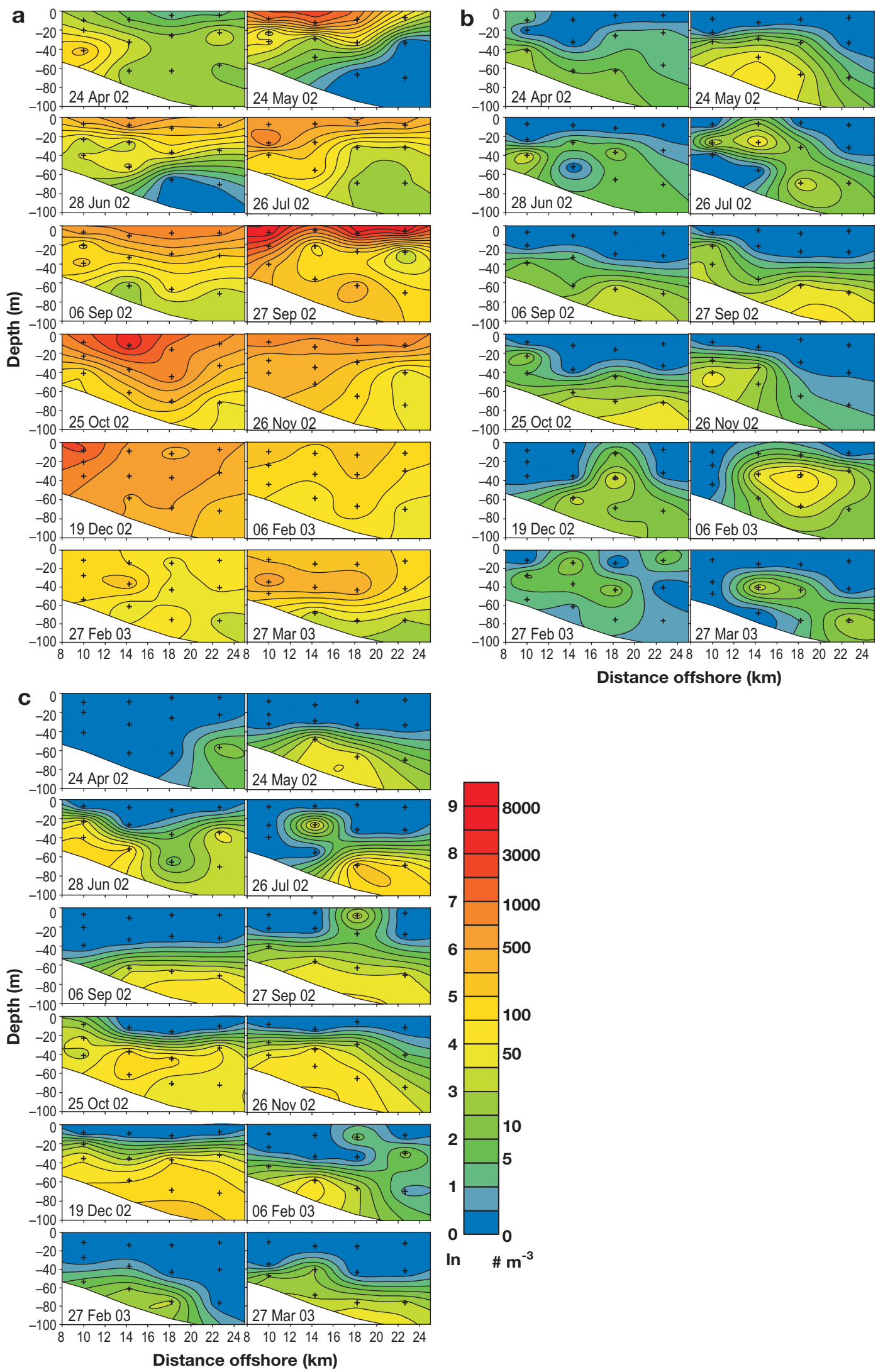

Fig. 6. Monthly section plots of individual species' densities. +: average depth sampled by each MOCNESS net. Copepod densities are shown at the same scale in each figure. (a) Oithona similis; (b) Metridia lucens; (c) Microcalanus pusillus 
a
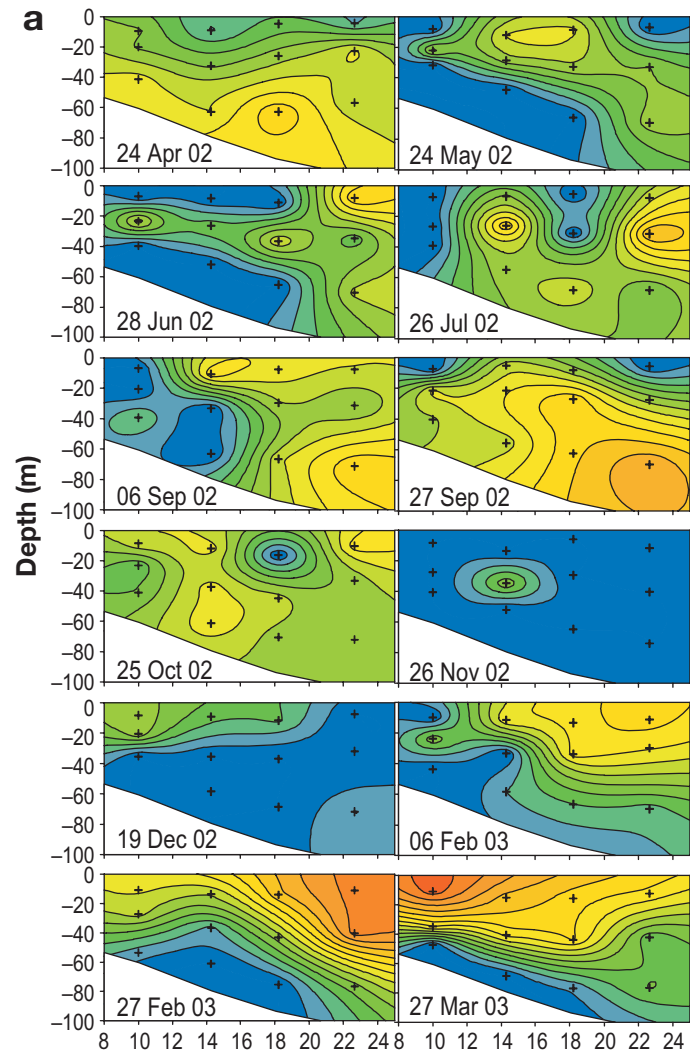

C
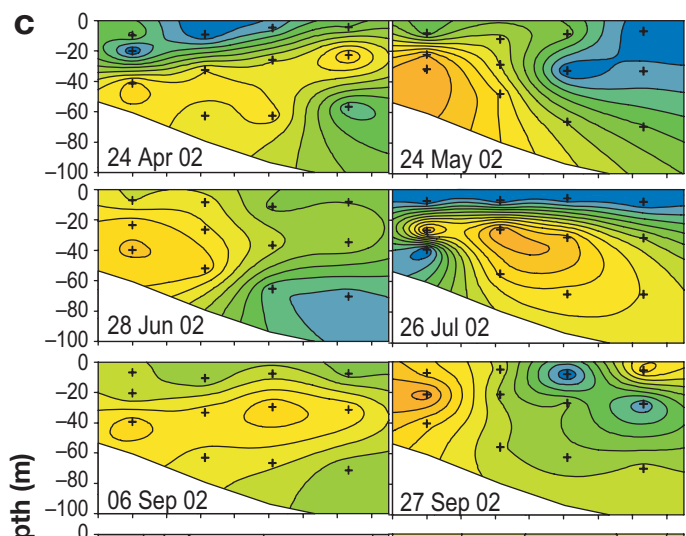

总

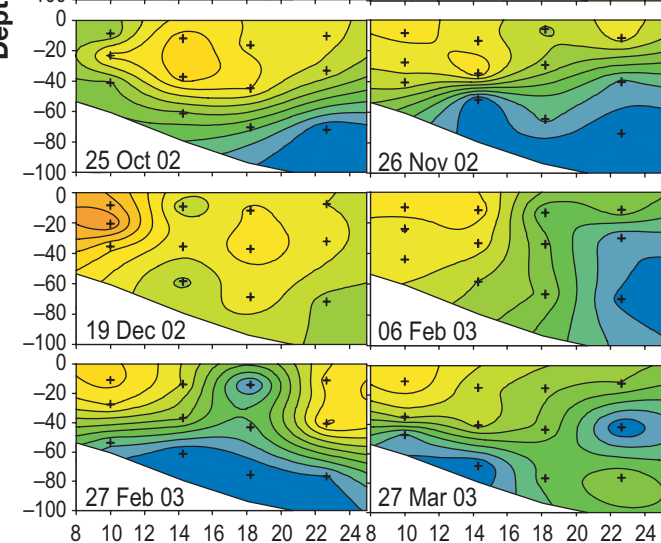

$810121416182022 \quad 248101214161820 \quad 2224$ Distance offshore (km)
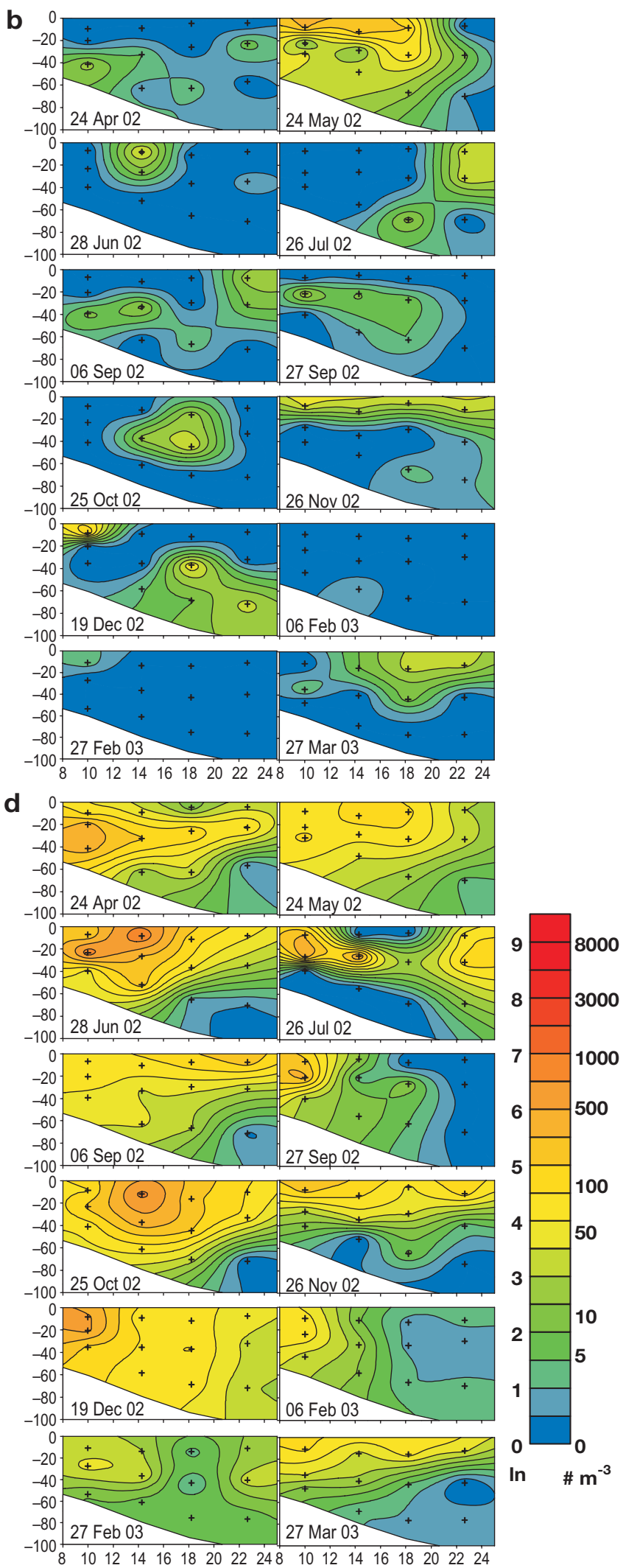

Distance offshore (km)

Fig. 7. Section plots as in Fig. 6. (a) Calanus finmarchicus; (b) Oithona atlantica; (c) Pseudocalanus moultoni; (d) P. newmani 
a
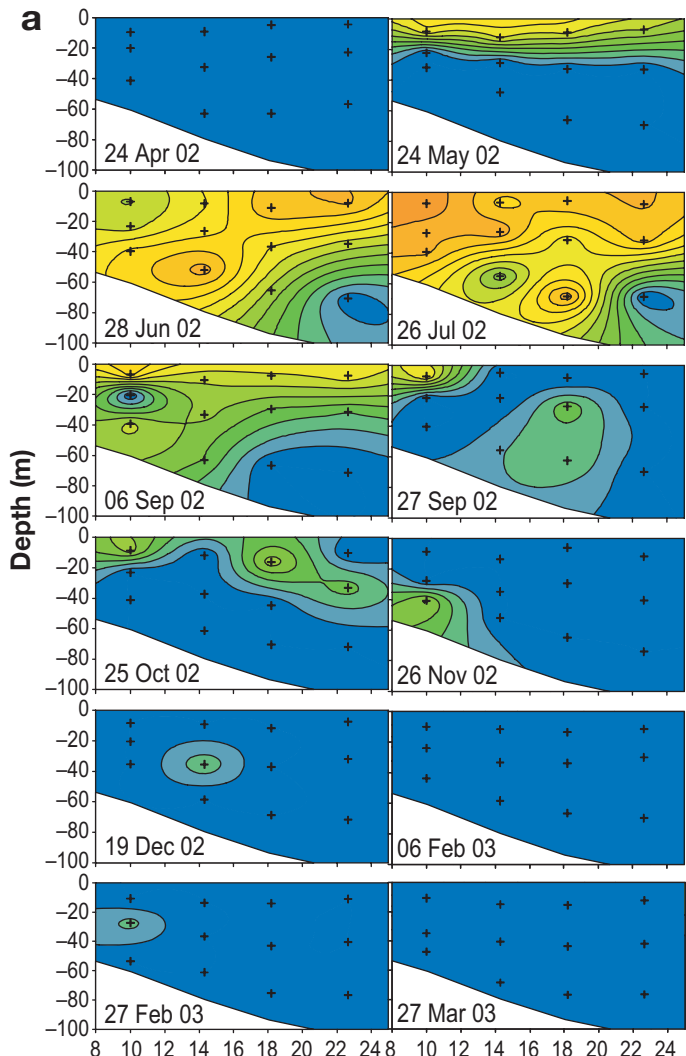

c
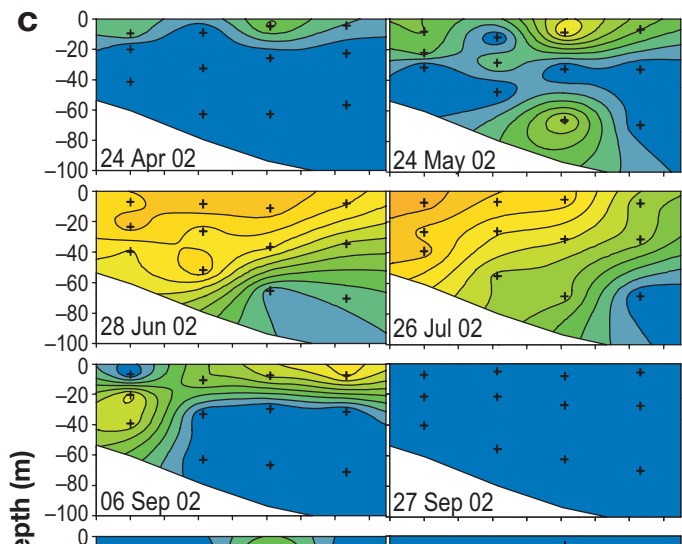

产
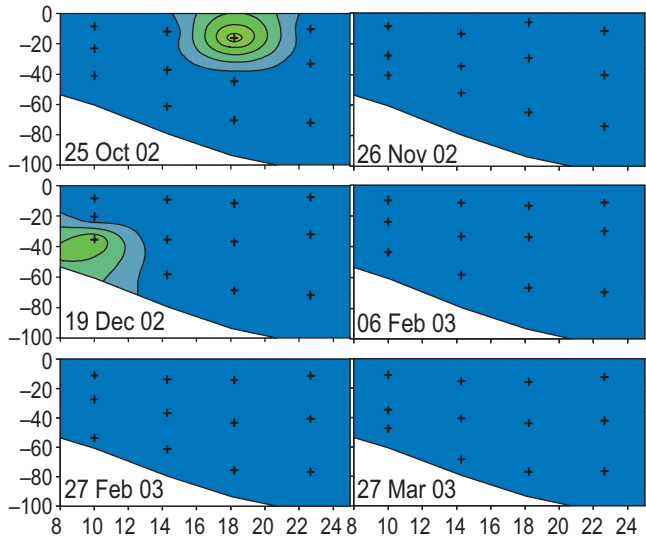

Distance offshore $(\mathrm{km})$
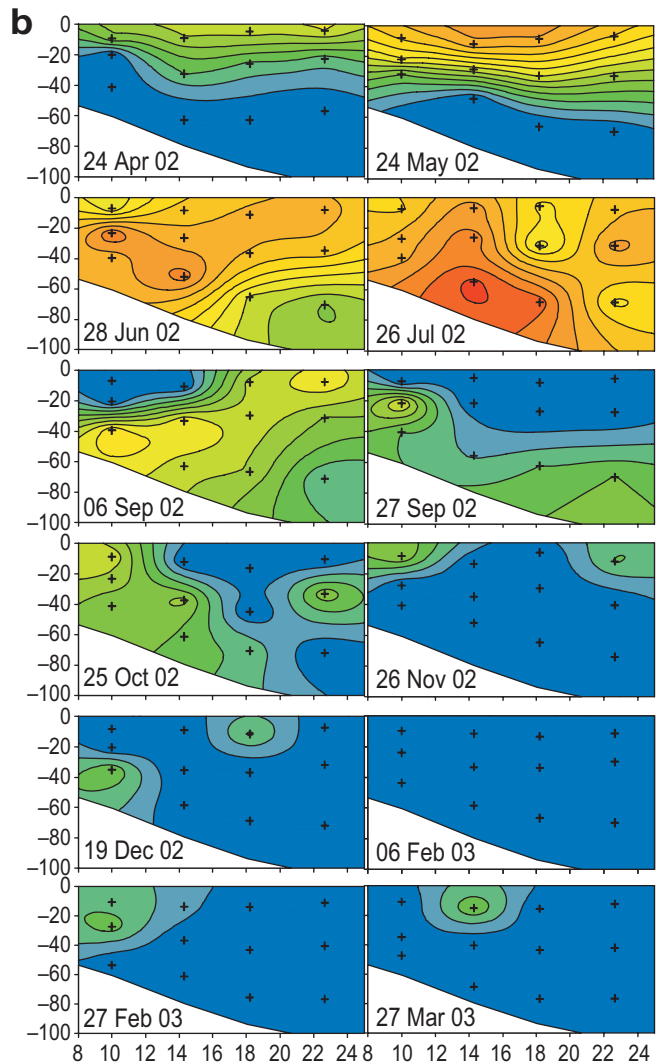

d
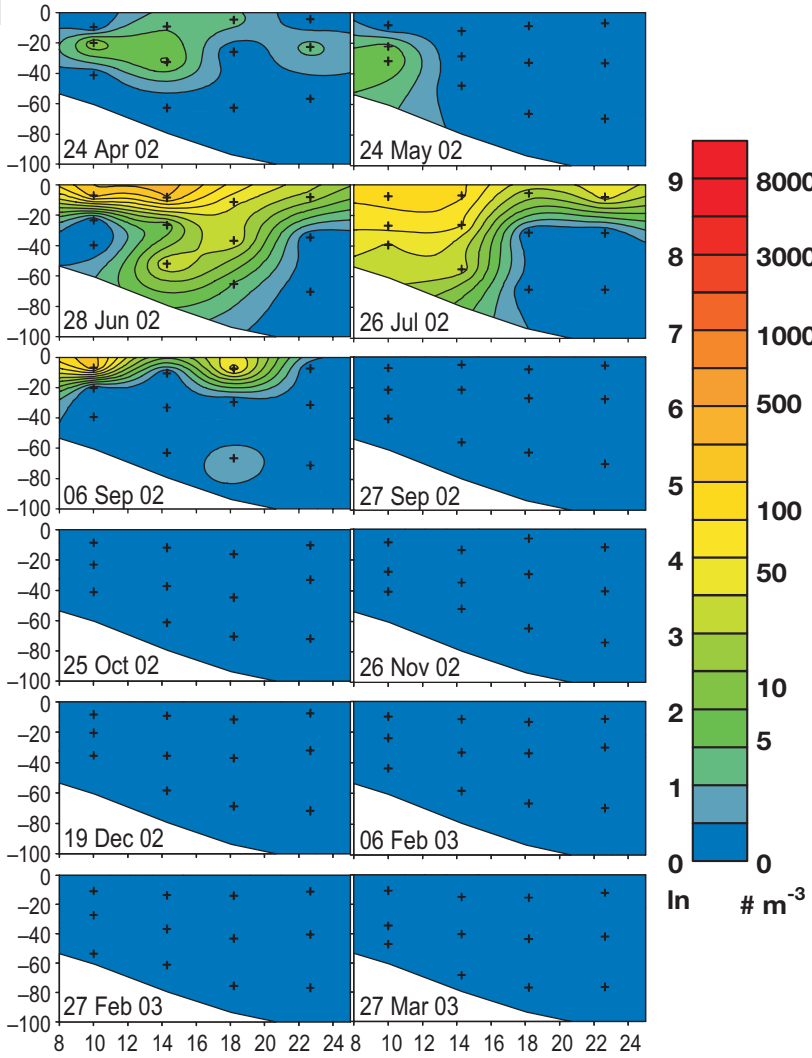

Distance offshore $(\mathrm{km})$

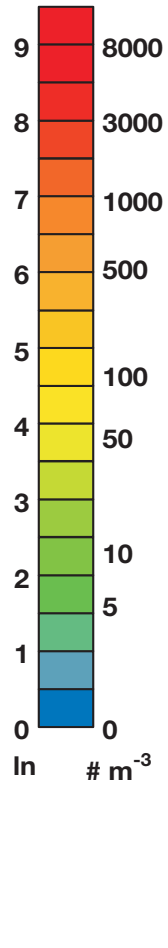

Fig. 8. Section plots as in Fig. 6. (a) Acartia hudsonica; (b) A. longiremis; (c) Centropages hamatus; (d) Eurytemora herdmani 

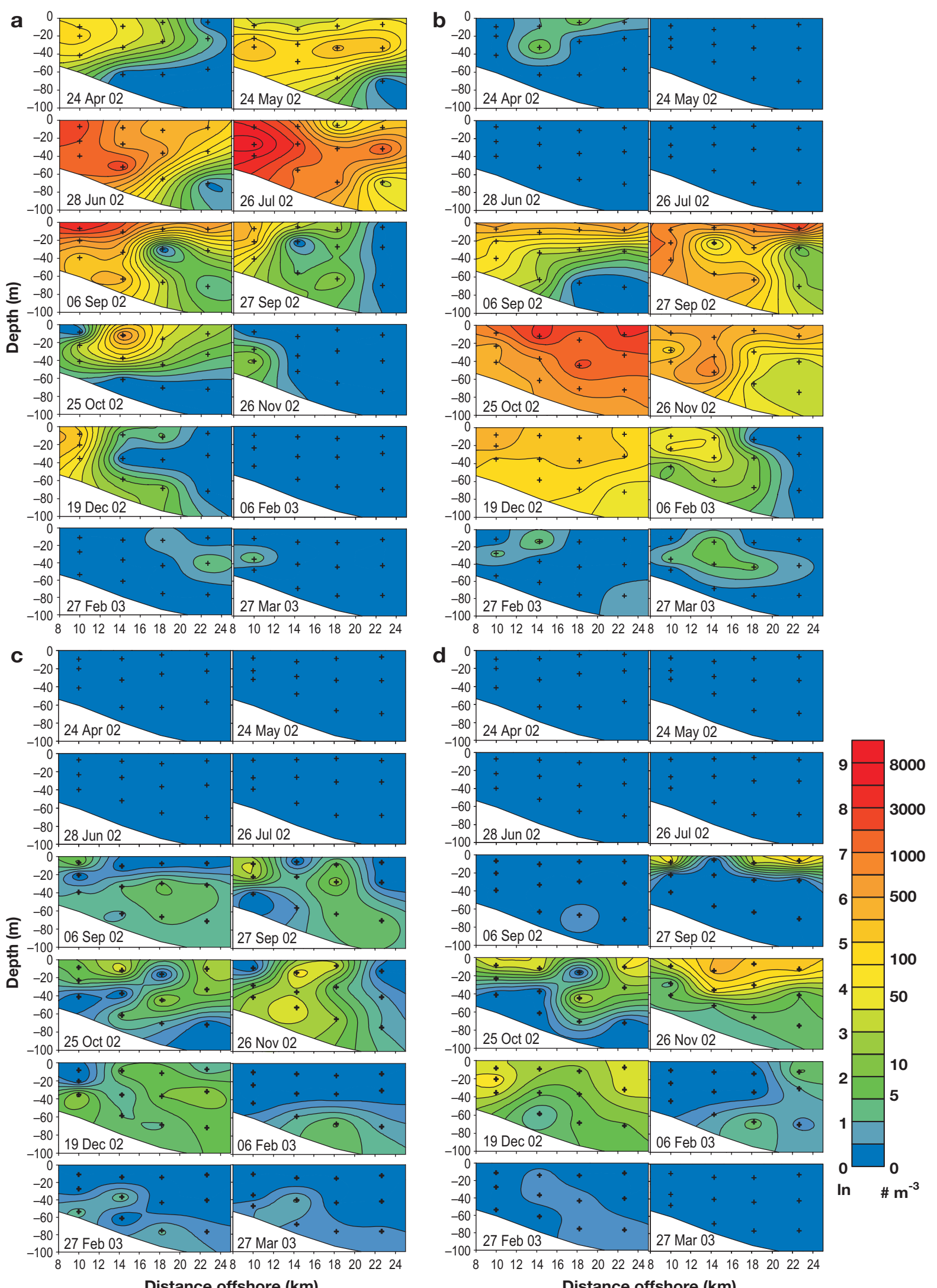

Distance offshore (km)

Fig. 9. Section plots as in Fig. 6. (a) Temora longicornis; (b) Centropages typicus; (c) Clausocalanus pergens; (d) Paracalanus parvus 
community had consistent vertical structure at those stations. There was a significant effect of station only among the deep samples. In the surface and midwater samples (which were approximately the same depth range at each station), there was no consistent change in species composition among stations.
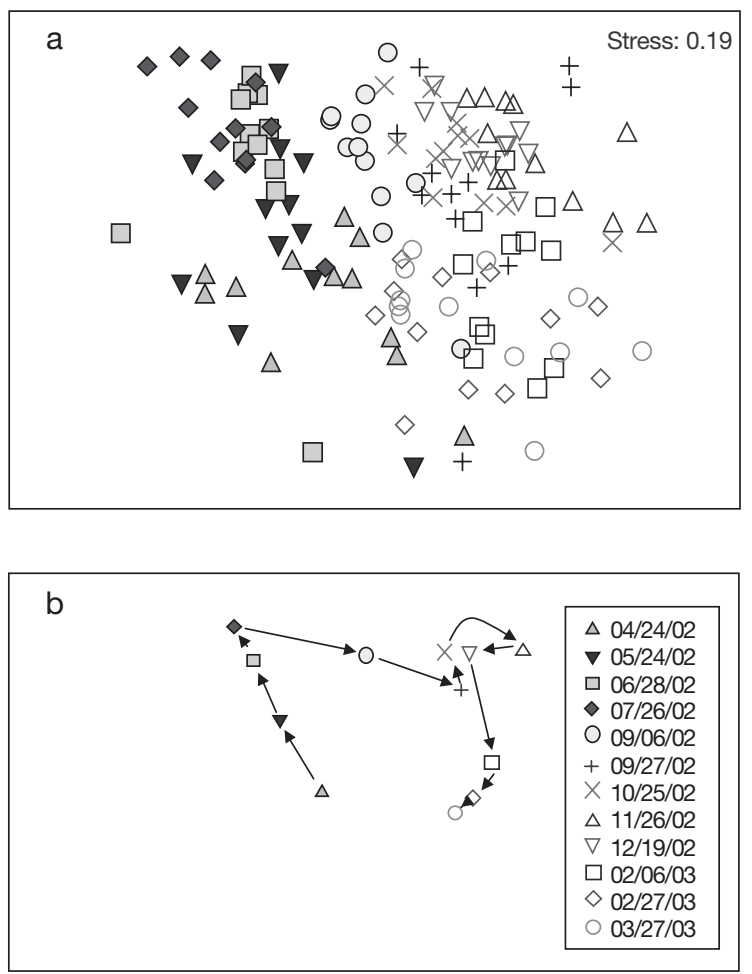

Fig. 10. MDS plots illustrating temporal variation in community structure. Greater proximity of points in the plot corresponds to greater similarity. (a) All samples. (b) Euclidian average for each month, showing generally cyclical pattern consistent with a seasonal cycle. Dates given as mo/d/yr

\section{DISCUSSION}

\section{Temporal patterns of species' abundance}

The greatest variation in the composition of the WMCR copepod community was associated with temporal change. On average and considering only the adults, the number of species recorded in the WMCR was higher from July to November than other times of the year. This was largely due to the presence of seasonally abundant species that were absent during winter months. Seven of the species sampled in this study had seasonal abundance peaks, with periods of scarcity or absence; 5 species were abundant yearround, with minimal seasonal fluctuation. A clear sea- sonal cycle of species' abundances is revealed by the MDS plot, in which the points are clustered by sample date rather than by depth or station (Fig. 10). If the pattern had been driven by spatial variability, the MDS plot would have shown clustering of the samples collected at each station. Importantly, the 4 stations were sufficiently closely spaced to reveal the temporal, rather than spatial, variability of the WMCR.

What factors enable one species to exist as adults year-round, while others do not? Seasonal specialization may be a result of a physiological limitation, such that individual mortality is dramatically higher outside a certain time period. Biological limitation may also drive seasonal peaks in abundance, through predatory control of population growth in the short term, and natural selection to avoid seasonally abundant predators (such as larval fish) in the long term. Physical transport controlled by the direction and speed of the Western Maine Coastal Current likely has a large influence over seasonal patterns as seen in the WMCR. Weak summer currents may allow copepod populations to bloom locally before being advected south by stronger fall currents (Fig. 3). The transport of organisms through the study site prevents us from concluding that the observed seasonal patterns are characteristic of patterns throughout a species' range. Additionally, though interannual variation in species' abundances in the WMCR is likely to be high (Sherman et al. 1998, Licandro et al. 2001, Plourde et al. 2002), the order and timing of peak abundances observed in this study may accurately represent the typical pattern of community dynamics for the region (Mazzocchi \& Ribera d'Alcala 1995).

\section{Horizontal spatial variability of species' abundances}

There was no significant variation among stations in species' abundances for surface and mid-water samples (Table 2). The similarity of samples at these depth strata indicated that horizontal patchiness did not alias the observed temporal patterns significantly. It is possible that patches were either large enough, so the 4 stations consistently fell within the same patch, or small enough, so the tow length integrated across several patches (see Haury \& Wiebe 1982). In either case, considerable variation in community structure may have been missed by the sampling used in this study. Future studies of the region will benefit by increasing both the vertical and horizontal resolution of sampling.

In contrast, there was significant variation among stations for the deep stratum (Table 2). The significant influence of station on the community sampled in the 
24 April 2002

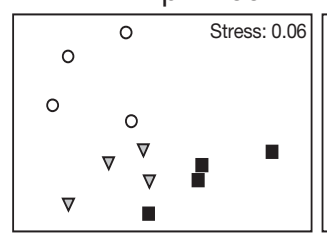

24 May 2002
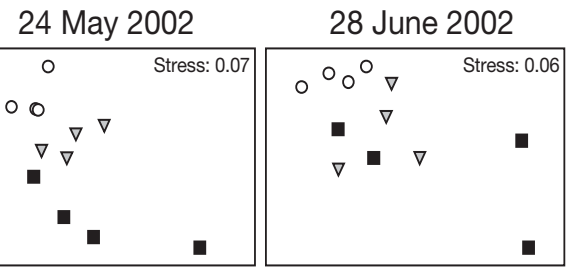

26 July 2002

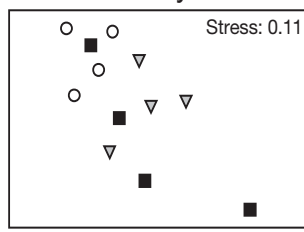

06 September 2002

27 September 2002

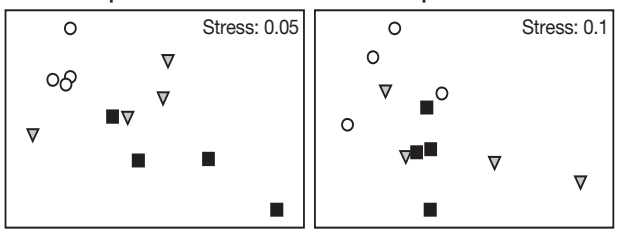

25 October 2002

26 November 2002

19 December 2002

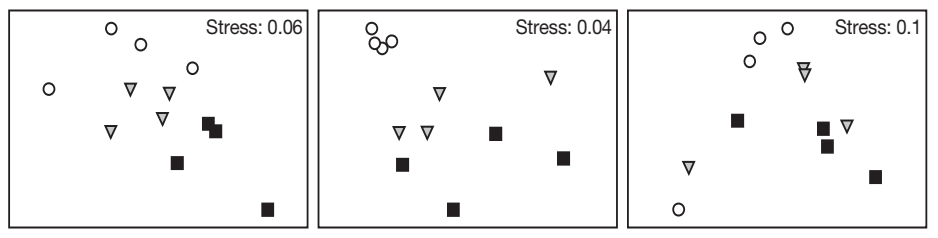

06 February $2003 \quad 27$ February 2003

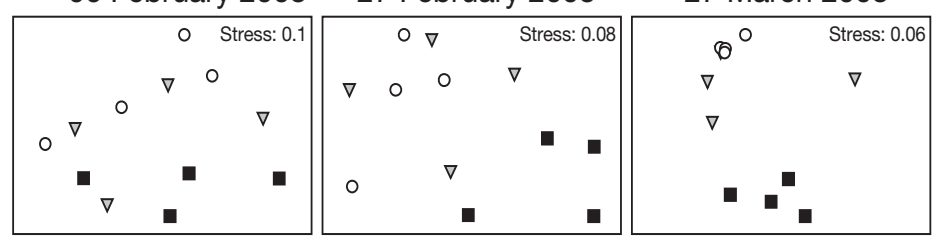

Fig. 11. MDS plots of individual months, showing surface (o), midwater $(\nabla)$, and deep ( $\mathbf{\square})$ samples for each station. Greater proximity of points in the plot corresponds to greater similarity. In many months, clustering of the same depth among the 4 stations is apparent peared to be influenced by the stratification of the water column. The significant vertical partitioning of the copepod community was indicated by the tendency of samples to cluster by depth rather than by station in the monthly MDS plots (Fig. 11). The significant differences among depths at Stns B, C, and D were mostly due to a consistent set of species, including Oithona similis, Metridia lucens, Microcalanus pusillus, Eurytemora herdmani, and both species of Centropages, which showed strong affinities for certain depths. Considered together, these findings clearly revealed the significance of depth-rather than horizontal placement-in determining copepod species abundances.

The observed spatial patterns may result from active swimming behaviors of individual copepods responding to physical cues, and/or from passive transport in a distinct water mass. For example, Acartia spp. may have been transported across the transect in a spring lowsalinity surface plume; seasonal vertical migration of Calanus finmarchicus is likely to have caused the observed switch between the deep distribution through much of the year and surface distribution in spring. Several species showed different vertical distributions during stratified and mixed periods (e.g. Oithona similis, Fig. 6a; Centropages typicus, Fig. 9b), with strong vertical gradients in abundance in stratified waters in summer, and more uniform distributions with mixing in the fall. Whether the seasonal shift was due to the inability of these species to maintain their vertical positions in the water column or the lack of strong physical gradients to cue active swimming behaviors is unknown. Strong diel vertical migration

strata was likely driven by the increasing dep of the cross-shelf transect. Stn D was deeper than $100 \mathrm{~m}$ and the deep sample at this station may be more typical of the Gulf of Maine basins than the coastal current.

\section{Vertical partitioning of species' abundances}

Vertical position in the water column is of considerable ecological significance for zooplankton, since this may markedly impact the direction and speed of advective transport, due to differences in currents throughout the water column (Hannah et al. 1997). Species found primarily in surface waters may be transported through the WMCR up to 5 times more rapidly than species found at depth (Fig. 3).

Many copepod species in the WMCR exhibited strong vertical gradients in abundance, which ap-
Table 2. ANOSIM2 tests for significance of Sample date, Depth, and Station. Statistical significance is determined for Bonferroni-corrected p values (Station, $\mathrm{n}=8$; Depth, $\mathrm{n}=6$ ). ${ }^{*} p<0.05,{ }^{* *} p<0.01,{ }^{* * *} p<0.001,{ }^{* * * *} p<0.0001$. See text for explanation of $\rho$ value

\begin{tabular}{|llll|}
\hline & Sample date & Depth & Station \\
\hline Station & & & \\
A & $\rho=0.682^{* * * *}$ & $\rho=0.053$ & - \\
B & $\rho=0.609^{* * *}$ & $\rho=0.417^{*}$ & - \\
C & $\rho=0.526^{* * *}$ & $\rho=0.485^{* *}$ & - \\
D & $\rho=0.369^{* * *}$ & $\rho=0.462^{*}$ & - \\
Depth & & & \\
Surface & $\rho=0.628^{* * * *}$ & - & $\rho=0.067$ \\
Midwater & $\rho=0.53^{* * * *}$ & - & $\rho=0.039$ \\
Deep & $\rho=0.543^{* * * *}$ & - & $\rho=0.603^{* * * *}$ \\
\hline
\end{tabular}


behavior likely explained the concentration of Metridia lucens (Fig. 6b) in deeper water in a fully mixed water column, although the causes of the deep concentration of Microcalanus pusillus (Fig. 6c) are less clear.

\section{Comparisons among congeneric species}

Three pairs of congeners were sufficiently abundant to allow comparisons of their spatial and temporal patterns. Acartia longiremis and A. hudsonica showed considerable overlap, with both species appearing in the surface waters by late May, and extending throughout the water column in June and July, although A. hudsonica was distributed evenly, while $A$. longiremis reached highest abundances in the deep samples (Fig. 12a). In contrast, overlap between Centropages typicus and C. hamatus was minimal. Although both species were present in slightly greater densities in the surface samples, they only co-occurred in 1 mo (Fig. 12b). C. hamatus and $C$. typicus are not temporally separated throughout much of their range (Kane 1997, 1999). Pseudocalanus moultoni and $P$. newmani were present throughout the year but, during stratification, $P$. moultoni was more abundant in deep samples, while $P$. newmani was much more concentrated at the surface (Fig. 12c). This pattern was most clearly seen by comparing only the surface and deep samples, since the midwater net necessarily samples from both above and below the pycnocline (Fig. 13). With the start of vertical mixing, this pattern of vertical segregation was erased.

\section{Sources of error in the analysis of temporal and spatial patterns}

This description of the WMCR copepod community in this study is incomplete due to the nature of the sampling program. Vertical abundance patterns of species
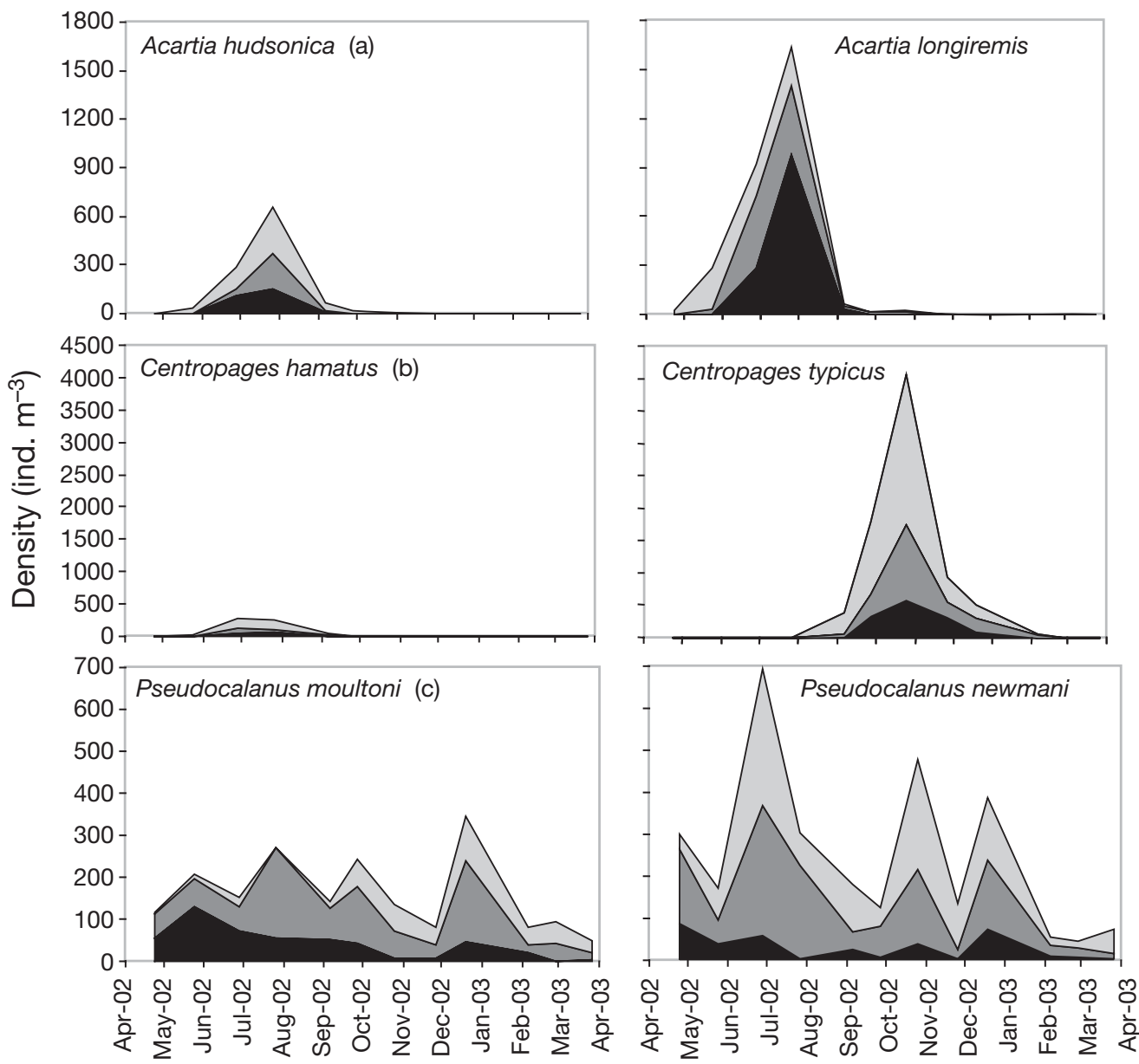

Fig. 12. Abundance patterns of congeneric species, averaged across stations. Shading indicates depth: surface (light gray), midwater (dark gray), and deep (black). Each pair of congeners is plotted on the same scale; scales differ among pairs. (a) Acartia hudsonica and A. longiremis, (b) Centropages hamatus and C. typicus, (c) Pseudocalanus moultoni and P. newmani 
are subject to short-term variation, with the occurrence of low-salinity plumes, changing thermocline depths, wind-induced turbulence (Incze et al. 2001), and presence of predators (Ohman 1990, Bollens \& Frost 1990, Frost \& Bollens 1992). Also, sampling was undertaken only during daylight hours, so the consequences of diel vertical migration were not detected. This is a topic that merits future study, since many of the species observed in this study exhibit diel vertical migration, including Acartia spp., Metridia lucens, Temora longicornis, and others (see e.g. Williams et al. 1994, Hays 1995). Spatial scales of sampling may have aliased the results (as discussed above) and the contour analysis may inaccurately portray some spatial patterns. These section plots (Figs. 6 to 9) are provided to allow visualization of the patterns; data points are indicated to allow accurate interpretation.

\section{Comparisons among coastal regions}

Many copepod species recorded in this study have also been documented on Georges Bank and in Massachusetts Bay (Bigelow 1924, Kane 1993, Turner 1994). However, there are notable differences in relative species' abundances, seasonal patterns, and peak timing from one region to another. In the WMCR, Oithona similis, Temora longicornis, and Centropages typicus predominated; the dominant species on Georges Bank were C. hamatus, C. typicus, and Calanus finmarchicus (Kane 1993); and in Massachusetts Bay were $O$. similis, Paracalanus parvus, and Pseudocalanus newmani (Turner 1994). Four WMCR species (C. hamatus, C. typicus, P. parvus, and T. longicornis) were highly seasonal, although they were abundant year-round in one or both of the other regions (Davis 1987, Turner 1994). Conversely, Pseudocalanus spp. had a strong summer peak on Georges Bank (Davis 1987), but neither $P$. moultoni nor $P$. newmani showed seasonal peaks in abundance in the WMCR. Only 2 of the abundant species in Massachusetts Bay exhibited seasonal abundance trends (Acartia hudsonica and A. tonsa, Turner 1994).

The observed differences in temporal patterns of species abundance between the WMCR, Georges Bank, and Massachusetts Bay may be a result of varying physical characteristics. Georges Bank does not receive direct estuarine output and thus despite its shallow water, it differs from true coastal regions. Much of the Massachusetts Bay area sampled by Turner (1994) is shallower than water sampled in this research. Additionally, due to dissimilar circulation patterns (e.g. along-shore flow in the WMCR and the summer recirculation on Georges Bank) the retention time is likely quite different between these areas.

Another reason for differences among these communities may be variation in the type and abundance of predators. Predation has been argued to be the architect of zooplankton community structure (Hayward \& McGowan 1979, McGowan \& Walker 1979). The presence of an abundant predator on Georges Bank may suppress a copepod species that is dominant in regions where that predator is absent. Predation effects also include feeding on naupliar stages by other copepods, so the abundance of one species may directly affect the abundance of others. As more studies shed light on the feeding preferences of each species, the importance of interactions among species in determining community composition will become clearer.

Differences in seasonal patterns of species' abundances suggest that the population dynamics and community interactions may differ among these adjacent regions. These comparisons must be interpreted cautiously, since the studies were conducted in different years, using different sampling gears. However, studies in other regions have shown that seasonal patterns of zooplankton species' abundance may be consistent from year to year (e.g. Mazzocchi \& Ribera d'Alcala
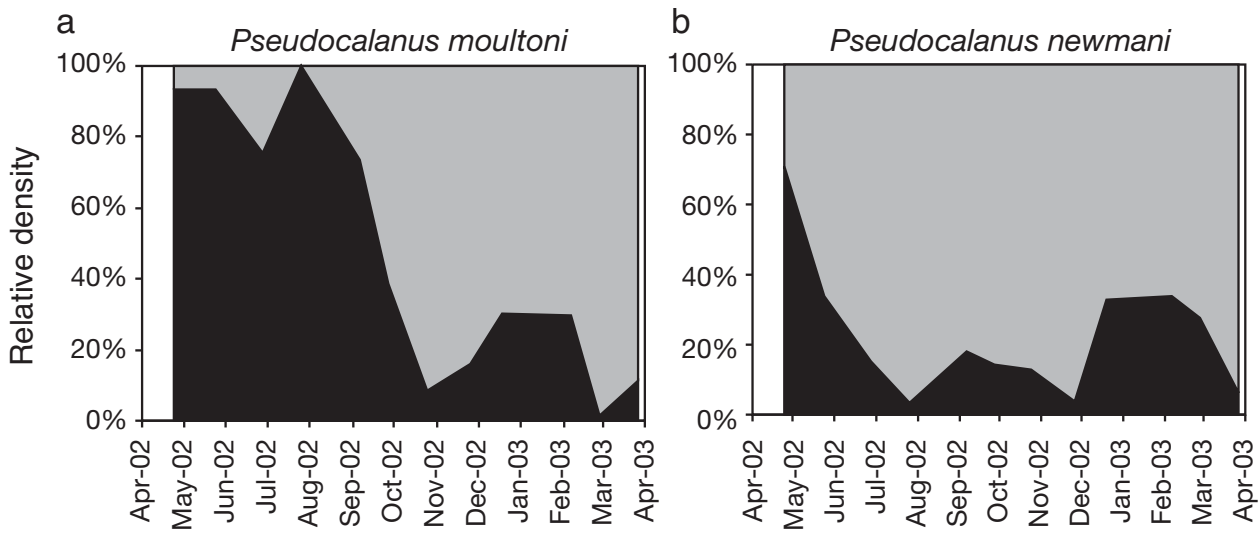

Fig. 13. Relative densities of (a) Pseudocalanus moultoni and (b) P. newmani as a function of depth. Shading indicates depths: surface (light gray), deep (black). Samples are averaged across stations 
1995), suggesting that regional comparisons spanning different years may be of value.

This study of the WMCR indicates that adjacent coastal regions may exhibit notably different patterns and seasonal peaks in relative species' abundances. These may result from interactions with different prey, predator, and competitor species, and may in turn cause and maintain ecologically important dissimilarities between the zooplankton communities of each region. This study further demonstrates that accurate assessment of the population dynamics, ecological interactions, and community composition of zooplankton within a region requires sampling at appropriate time and space scales.

Acknowledgements: We would like to thank the crew of the R/V 'Gulf Challenger' P. E. Pelletier, B. J. Soares and D. H. Brewitt (all at the University of New Hampshire, UNH), whose skill and patience were critical to the success of this project. J. G. Beaudet and S. B. Smolenack (both at UNH) helped with sample collection. P. H. Wiebe (Woods Hole Oceanographic Institution) provided invaluable MOCNESS assistance. N. J. Copley (Woods Hole Oceanographic Institution) and B. W. Frost (University of Washington) verified species identification. Funding was provided by the UNH Hubbard Marine Program Endowment and UNH's Center of Excellence for Coastal Ocean Observation and Analysis (COOA).

\section{LITERATURE CITED}

Ambler JW, Miller CB (1987) Vertical habitat-partitioning by copepodites and adults of subtropical oceanic copepods. Mar Biol 94(4):561-577

Bigelow HB (1924) Plankton of the offshore waters of the Gulf of Maine. Bull US Bur Fish 40(2):1-509

Bisagni JJ, Gifford DJ, Ruhsam CM (1996) The spatial and temporal distribution of the Maine Coastal Current during 1982. Cont Shelf Res 16:1-24

Bollens SM, Frost BW (1990) UV light and vertical distribution of the marine planktonic copepod Acartia hudsonica Pinhey. J Exp Mar Biol Ecol 137(2):89-93

Bucklin A, Benthley AM, Franzen SP (1998) Distribution and relative abundance of Pseudocalanus moultoni and $P$. newmani (Copepoda: Calanoida) on Georges Bank using molecular identification of sibling species. Mar Biol 132(1): 97-106

Bucklin A, Guarnieri M, McGillicuddy DJ, Hill RS (2001) Spring evolution of Pseudocalanus spp. abundance on Georges Bank based on molecular discrimination of $P$. moultoni and P. newmani. Deep-Sea Res 48(1-3):589-608

Clarke K (1993) Non-parametric multivariate analyses of changes in community structure. Aust J Ecol 18:117-143

Clarke K, Warwick R (1994) Similarity-based testing for community pattern: the 2 -way layout with no replication. Mar Biol 118:167-176

Davis C (1987) Zooplankton life cycles. In: Backus R (ed) Georges Bank. The MIT Press, Cambridge, MA, p 256-267

Davis CSW, Wiebe PH (1985) Macrozooplankton biomass in a warm-core Gulf Stream ring: time series changes in size structure, taxonomic composition, and vertical distribution. J Geophys Res 90(C5):8871-8884
Durbin E (1997) Zooplankton dynamics of the Gulf of Maine and Georges Bank region. In: Wallace GT, Braasch EF (eds) Proceedings of the Gulf of Maine Ecosystem Dynamics Scientific Symposium and Workshop, Regional Association for Research on the Gulf of Maine, Hanover, $\mathrm{NH}$, p 53-67

Frost BW (1989) A taxonomy of the marine calanoid copepod genus Pseudocalanus. Can J Zool 67(3):525-551

Frost BW, Bollens SM (1992) Variability of diel vertical migration in the marine planktonic copepod Pseudocalanus newmani in relation to its predators. Can J Fish Aquat Sci 49(6):1137-1141

Gerber R (1999) An identification manual to the coastal and estuarine zooplankton of the Gulf of Maine region. Acadia Productions, Brunswick

Hannah CG, Naimie CE, Loder JW, Werner FE (1997) Upperocean transport mechanisms from the Gulf of Maine to Georges Bank, with implications for Calanus supply. Cont Shelf Res 17(15):1887-1911

Haury LR, Wiebe PH (1982) Fine-scale multi-species aggregations of oceanic zooplankton. Deep-Sea Res 29(7A): 915-921

Hays GC (1995) Ontogenetic and seasonal variation in the diel vertical migration of the copepods Metridia lucens and Metridia longa. Limnol Oceanogr 40(8):1461-1465

Hayward TL, McGowan JA (1979) Pattern and structure in an oceanic zooplankton community. Am Zool 19(4): 1045-1055

Incze LS, Hebert D, Wolff N, Oakey N, Dye D (2001) Changes in copepod distributions associated with increased turbulence from wind stress. Mar Ecol Prog Ser 213:229-240

Johnson MW (1934) The life history of the copepod Tortanus discaudatus (Thompson and Scott). Biol Bull (Woods Hole) 67(1):182-200

Kane J (1993) Variability of zooplankton biomass and dominant species abundance on Georges Bank, 1977-1986. Fish Bull US 91(3):464-474

Kane J (1997) Persistent spatial and temporal abundance patterns for late-stage copepodites of Centropages hamatus (Copepoda: Calanoida) in the U.S. northeast continental shelf ecosystem. Fish Bull US 95:85-98

Kane J (1999) Persistent spatial and temporal abundance patterns for the late-stage copepodites of Centropages typicus (Copepoda: Calanoida) in the US Northeast Continental Shelf ecosystem. J Plankton Res 21(6): 1043-1064

Lagadeuc Y, Boule M, Dodson JJ (1997) Effect of vertical mixing on the vertical distribution of copepods in coastal waters. J Plankton Res 19(9):1183-1204

Lawson TJ, Grice GD (1970) The developmental stages of Centropages typicus Kroyer (Copepoda, Calanoida). Crustaceana 18(2):187-209

Licandro P, Conversi A, Ibanez F, Jossi J (2001) Time series analysis of interrupted long-term data set (1961-1991) of zooplankton abundance in Gulf of Maine (northern Atlantic, USA). Oceanol Acta 24(5):453-466

Mazzocchi MG, Ribera d'Alcala M (1995) Recurrent patterns in zooplankton structure and succession in a variable coastal environment. ICES J Mar Sci 52(3-4):679-691

McGillicuddy DJ Jr, Lynch DR, Moore AM, Gentleman WC, Davis CS, Meise CJ (1998) An adjoint data assimilation approach to diagnosis of physical and biological controls on Pseudocalanus spp. in the Gulf of Maine-Georges Bank region. Fish Oceanogr 7(3-4):205-218

McGowan JA, Walker PW (1979) Structure in the copepod community of the North Pacific Central Gyre. Ecol Monogr 49(2):195-226 
Murphy JA, Cohen RE (1978) A guide to the developmental stages of common coastal, Geroges Bank and Gulf of Maine copepods. National Marine Fisheries Service, Northeast Fisheries Center. Woods Hole Laboratory, Massachusetts. Laboratory Reference No. 78-53

Ohman MD (1990) The demographic benefits of diel vertical migration by zooplankton. Ecol Monogr 60(3):257-281

Pielou E (1975) Ecological diversity. Wiley-Interscience, New York

Plourde S, Dodson JJ, Runge JA, Therriault JC (2002) Spatial and temporal variations in copepod community structure in the lower St. Lawrence Estuary, Canada. Mar Ecol Prog Ser 230:211-224

Sherman K, Solow A, Jossi J, Kane J (1998) Biodiversity and abundance of the zooplankton of the Northeast Shelf ecosystem. ICES J Mar Sci 55(4):730-738

Turner JT (1994) Planktonic copepods of Boston Harbor,

Editorial responsibility: Kenneth Sherman, (Contributing Editor) Narragansett, Rhode Island, USA
Massachusetts Bay and Cape Cod Bay, 1992. Hydrobiologia 292/293:405-413

Wiafe G, Frid CLJ (1996) Short-term temporal variation in coastal zooplankton communities: the relative importance of physical and biological mechanisms. J Plankton Res 18(8):1485-1501

Wiebe PH, Morton AW, Bradley AM, Backus RH, Craddock JE, Barber V, Cowles TJ, Flierl GR (1985) New developments in the MOCNESS, an apparatus for sampling zooplankton and micronekton. Mar Biol 87(3):313-323

Williams R, Conway DVP, Hunt HG (1994) The role of copepods in the planktonic ecosystems of mixed and stratified waters of the European shelf seas. Hydrobiologia 292/293: 521-530

Wilson C (1932) The copepods of the Woods Hole region. United States Government Printing Office, Washington, DC

Submitted: March 30, 2004; Accepted: November 4, 2004 Proofs received from author(s): April 19, 2005 